\title{
Many Canadians Feel Healthcare Needs Are Not Being Met
}

\author{
Lyn M. Sibley and Richard H. Glazier
}

\section{The Issue}

There is a growing shortage of healthcare providers in Canada particularly primary care practitioners. In 2007, it was estimated that $15 \%$ of Canadians aged 12 and older did not have a regular family physician (ranging from $6 \%$ in Nova Scotia to $26 \%$ in Quebec); and in 2008, 9\% did not have a regular source of care (Canadian Institute for Health Information 2009). Even those who do have a regular source of care may still have difficulty gaining access to necessary care. In 2008, $13 \%$ of Canadians who required routine or ongoing care and $21 \%$ of those requiring immediate care experienced difficulty obtaining it (Canadian Institute for Health Information 2009).

\section{In 2008, 13\% of Canadians who required routine or ongoing care and $21 \%$ of those requiring immediate care experienced difficulty obtaining it.}

Self-perceived unmet healthcare need is commonly used as an indicator of access to healthcare. Research using data from the Canadian Community Health Survey (CCHS 1.1) and the National Population Health Survey (NPHS) has shown that the proportion of people reporting unmet healthcare needs rose from $4.2 \%$ in $1994-1995$ to three times that $(12.5 \%)$ in 2000-2001 (Sanmartin et al. 2002).

In order for policy makers to address a potential worsening in access to care, greater understanding is needed about the reasons healthcare needs are not being met and how these reasons vary by region and segment of the population. Reasons for unmet need can be classified into three categories: availability of services, accessibility to services and acceptability of available services. Because healthcare delivery and planning occur largely at the provincial level, it is useful to evaluate the reasons for unmet need by province.

A recent study conducted at the Institute for Clinical Evaluative Sciences (ICES) compared rates of self-perceived unmet need across provinces and assessed how the reported reasons for unmet need varied (Sibley and Glazier 2009).
Variation in determinants of unmet need, including demographic factors, health status and socioeconomic variables, were also examined.

\section{The Study}

This study used data from the CCHS 2.1 conducted in 2003. The CCHS sample for this study included 111,258 respondents aged 20 or older living in one of the 10 Canadian provinces. It is estimated that the survey represents approximately 22.6 million people or $69.5 \%$ of the Canadian population (Statistics Canada 2005).

Each respondent was asked, "During the past 12 months, was there ever a time when you felt that you needed healthcare but didn't receive it?" To learn about reasons for unmet need, respondents were asked, "Thinking of the most recent time, why didn't you get care?" The reported reasons were grouped into three categories: availability, accessibility and acceptability (Table 1), as previously reported by Chen and Hou (2002).

In this study, we constructed regression models to adjust for predictor variables related to access and use of healthcare services in the categories of contextual characteristics, need, predisposing characteristics and enabling factors (Andersen 1995). The statistical techniques of weighting and bootstrap re-sampling were used to account for the probability sampling used by the CCHS.

\section{Key Findings}

In 2003, 11.7\% of Canadians reported unmet healthcare needs in the previous 12 months. This report was highest in Manitoba (13.3\%) and lowest in Prince Edward Island (7.8\%).

The most common reason for unmet need was problems with availability of services (54.9\%), followed by acceptability (42.8\%) and accessibility (12.7\%). There was no consistent pattern by province or by reason (Figure 1). Residents of Quebec, Newfoundland and Manitoba were most likely to report unmet need due to problems of availability - the most common complaint related to availability was long waiting times. Residents of British Columbia and Alberta were most likely to have unmet need due to problems of accessibility related to cost 
or transportation. There was little provincial difference in unmet need due to problems of acceptability.

A comparison of all of the determinants of unmet need showed similar results across the categories of reasons, except for provinces for which there was large variation. People who lived in rural communities, had lower levels of education or were older were less likely to report having unmet healthcare needs overall or problems of availability and accessibility. People who had poorer health, had lower incomes, were women or did not have a regular medical doctor were more likely to report having unmet healthcare needs overall and for each of the three reasons. People who had low incomes or no pharmaceuticals insurance were more likely to report unmet need due to problems of cost or transportation.

\section{Problems of} availability were the most common reasons for unmet need - these problems have the greatest potential for policy intervention.

\section{Implications}

Problems of availability were the most common reasons for unmet need and had the most variation across provinces. These
Table 1. Reasons for self-perceived unmet need

\begin{tabular}{|l|c|l|c|l|l|}
\hline \multicolumn{2}{|l|}{ Lack of Availability } & \multicolumn{2}{l}{ Lack of Acceptability } & \multicolumn{2}{l|}{ Lack of Accessibility } \\
\hline Reason & $\%$ & Reason & $\%$ & Reason & $\%$ \\
\hline Waiting time too long & 35.6 & Felt it would be inadequate & 9.9 & Cost & 11.5 \\
\hline Not available when required & 16.5 & Other & 8.5 & Transportation & 1.6 \\
\hline Not available in area & 11.0 & Didn't get around to it & 8.4 & & \\
\hline & & Decided not to seek care & 7.9 & & \\
\hline & & Too busy & 7.1 & & \\
\hline & & Didn't know where to go & 3.7 & & \\
\hline & & Dislike doctors/afraid & 1.7 & & \\
\hline & & Personal/family responsibilities & 1.3 & & \\
\hline
\end{tabular}

Figure 1. Unmet need by reported reason

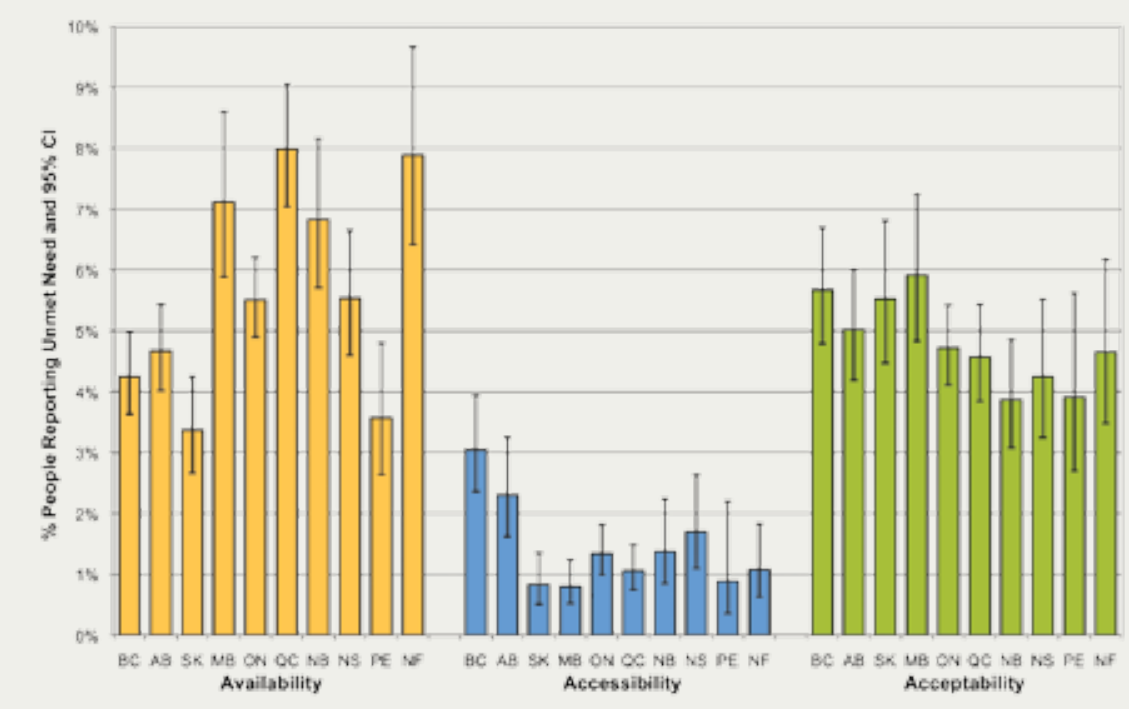

Adjusted for rural-urban status, chronic conditions, self-rated health, sex, age, marital status, educational attainment, ethnic origin, having a regular medical doctor, income adequacy, pharmaceutical insurance and occupation class.

problems have the greatest potential for policy intervention. Given that the most common single reason related to availability was "waiting time too long," particular attention should be focused on this issue. Little is known about waiting times for primary care; international comparisons show that Canada has a great deal of room to improve in access to primary care 
(Schoen et al. 2005; Walberg et al. 2009) and that enhanced access is possible through better scheduling practices, without increasing costs or healthcare personnel (Murray and Berwick 2003). There is also evidence that surgical wait times can be reduced by centralizing wait lists and wait-list management (Priest et al. 2007).

One strategy to address these potential barriers to access is to increase available services through the expansion of the patientcentred medical care home model of care. In both Canada and the United States, there is growing attention to patient-centred medical care homes (College of Family Physicians of Canada 2009; Rosser et al. 2010). These are multidisciplinary patient care settings where each patient has his or her own family physician who coordinates care with other health professionals and services. In a medical care home, patients have an electronic medical record and can expect timely appointments with their physician and other team members (Center for Policy Studies in Family Medicine and Primary Care 2007; College of Family Physicians of Canada 2009). Medical homes are being promoted because of their potential to increase appropriate preventive care measures and improve chronic disease management. Another important benefit of medical homes is that they are intended to attract physicians to specialize in family medicine. They also expand the primary care workforce by including non-physician care providers, such as physician assistants and nurse practitioners, in primary care teams. A number of provinces have started to adopt a strategy of patient-centred medical homes; most prominently, the Ontario Ministry of Health and Long-Term Care has introduced and continues to expand the coverage of family health teams (Rosser et al. 2010).

Telemedicine programs are another innovation that may improve the availability of healthcare services. Some areas of Canada have successfully implemented telemedicine programs that expand the delivery of dermatology, radiology, cardiology and diabetes services (Cheung et al. 1998; Dunscombe and Roberts 2001; Jin et al. 2003; Reid et al. 1998). Decentralized service delivery can also be implemented to reduce travel time from patients' homes to healthcare services and to decrease associated out-of-pocket costs (Roberts et al. 2002; Seto 2008).

The second most common category of reasons for unmet need is acceptability. Unmet need due to problems of acceptability present a quandary as they are generally related to personal preferences or circumstances of individuals and are, for the most part, unrelated to characteristics of healthcare services (with the possible exception of language). Further research to understand acceptability would help with the interpretation of this variable.

Residents of British Columbia and Alberta were most likely to report unmet need due to problems of accessibility. The majority of people who reported such problems cited cost as the primary barrier. It is unclear if this refers to direct out-ofpocket costs, costs related to travel or costs of insurance. There is no evidence that residents of British Columbia or Alberta pay higher out-of-pocket costs or insurance premiums (Luffman 2005). Costs may be related to how the population is distributed across the province and the fact that the majority of tertiary services are centralized at a few locations, therefore requiring people to take time away from work to travel long distances to receive healthcare. Telemedicine interventions may address some of these concerns. Further research should focus on why residents of British Columbia and Alberta are more likely to perceive cost-related barriers to healthcare services.

\section{Conclusions}

In this study, we compared self-perceived unmet needs and the reasons for them across the Canadian provinces. Among the $12 \%$ of Canadians reporting unmet health service needs, the leading reason was problems of availability of services (54.9\%). Recent innovations in how primary care is organized and funded may address some of this unmet need; however, more can be done to reduce waiting times. Further work is needed to address cost barriers to healthcare, particularly among lowerincome groups and in British Columbia and Alberta. HQ

\section{Acknowledgements}

This study was supported by ICES, which is funded by an annual grant from the Ontario Ministry of Health and Long-Term Care (MOHLTC). The opinions, results and conclusions reported in this article are those of the authors and are independent from the funding sources. No endorsement by ICES or MOHLTC is intended or should be inferred.

Lyn Sibley is supported by a post-doctoral fellowship from the Canadian Institutes of Health Research, Institute for Health Services and Policy Research.

\section{References}

Andersen, R.M. 1995. "Revisiting the Behavioral Model and Access to Medical Care: Does It Matter?" Journal of Health and Social Behavior 36(1): 1-10.

Canadian Institute for Health Information. 2009. Experiences with Primary Health Care in Canada. Ottawa, ON: Author. Retrieved March 11, 2010. <http://secure.cihi.ca/cihiweb/products/cse_phc_ aib_en.pdf>.

Center for Policy Studies in Family Medicine and Primary Care. 2007. The Patient Centered Medical Home: History, Seven Core Features, Evidence and Transformational Change. Washington, DC: Robert Graham Center. Retrieved March 11, 2010. <http://www.aafp.org/ online/etc/medialib/aafp_org/documents/about/pcmh.Par.0001.File. tmp/PCMH.pdf>.

Chen, J. and F. Hou. 2002. "Unmet Needs for Health Care." Health Reports 13(2): 23-34.

Cheung, S.T., R.F. Davies, K. Smith, R. Marsh, H. Sherrard and W.J. Keon. 1998. "The Ottawa Telehealth Project." Telemedicine Journal 4(3): 259-66.

College of Family Physicians of Canada. 2009. Patient-Centred Primary Care in Canada: Bring It On Home. Mississauga, ON: Author. 
Retrieved March 11, 2010. <http://www.cfpc.ca/local/files/ Communications/Health\%20Policy/Bring\%20it\%20on\%20 Home\%20FINAL\%20ENGLISH.pdf>.

Dunscombe, P. and G. Roberts. 2001. "Radiotherapy Service Delivery Models for a Dispersed Patient Population." Clinical Oncology (Royal College of Radiologists) 13(1): 29-37.

Jin, A.J., D. Martin, D. Maberley, K.G. Dawson, D.W. Seccombe and J. Beattie. 2003. "Evaluation of a Mobile Diabetes Care Telemedicine Clinic Serving Aboriginal Communities in Northern British Columbia, Canada." International Journal of Circumpolar Health 62(Suppl. 2): 124-28.

Luffman, J. 2005. "Out-of-Pocket Spending on Prescription Drugs." Perspectives on Labour and Income 6(9): 5-13.

Murray, M. and D.M. Berwick. 2003. "Advanced Access: Reducing Waiting and Delays in Primary Care." Journal of the American Medical Association 289(8): 1035-40.

Priest, A., A. Rachlis and M. Cohen. May 2007. Why Wait? Public Solutions to Cure Surgical Waitlists. Vancouver, BC: Canadian Centre for Policy Alternatives and the BC Health Coalition.

Reid, D.S., L.E. Weaver, J.M. Sargeant, M.J. Allen, W.F. Mason, P.J. Klotz et al. 1998. "Telemedicine in Nova Scotia: Report of a Pilot Study." Telemedicine Journal 4(3): 249-58.

Roberts, G.H., P.B. Dunscombe and R.S. Samant. 2002. "Geographic Delivery Models for Radiotherapy Services." Australasian Radiology 46(3): 290-4.

Rosser, W.W., J.M. Colwill, J. Kasperski and L. Wilson. 2010. "Patient-Centered Medical Homes in Ontario." New England Journal of Medicine 362(3): e7.

Sanmartin, C., C. Houle, S. Tremblay and J.M. Berthelot. 2002. "Changes in Unmet Health Care Needs." Health Reports 13(3): 15-21.

Schoen, C., R. Osborn, P.T. Huynh, M. Doty, K. Zapert, J. Peugh et al. 2005. "Taking the Pulse of Health Care Systems: Experiences of Patients with Health Problems in Six Countries." Health Affairs Suppl Web Exclusive: W5-509-25.

Seto, E. 2008. "Cost Comparison between Telemonitoring and Usual Care of Heart Failure: A Systematic Review." Telemedicine Journal and e-Health 14(7): 679-86.

Sibley, L.M. and R.H. Glazier. 2009. "Reasons for Self-Reported Unmet Healthcare Needs in Canada: A Population-Based Provincial Comparison." Healthcare Policy 5(1): 87-101.

Statistics Canada. 2005. Canadian Community Health Survey, 2003: User Guide for the Public Use Microdata File (Catalogue No. 82M0013XCB). Ottawa, ON: Ministry of Industry.

Walberg, M., A. Björnberg and R. Nagy. 2009. Euro-Canada Health Consumer Index 2008. Winnipeg, MB: Health Consumer Powerhouse and Frontier Centre for Public Policy. Retrieved March 11, 2010. <http://www.fcpp.org/pdf/ECHCI2008finalJanuary202008.pdf>.

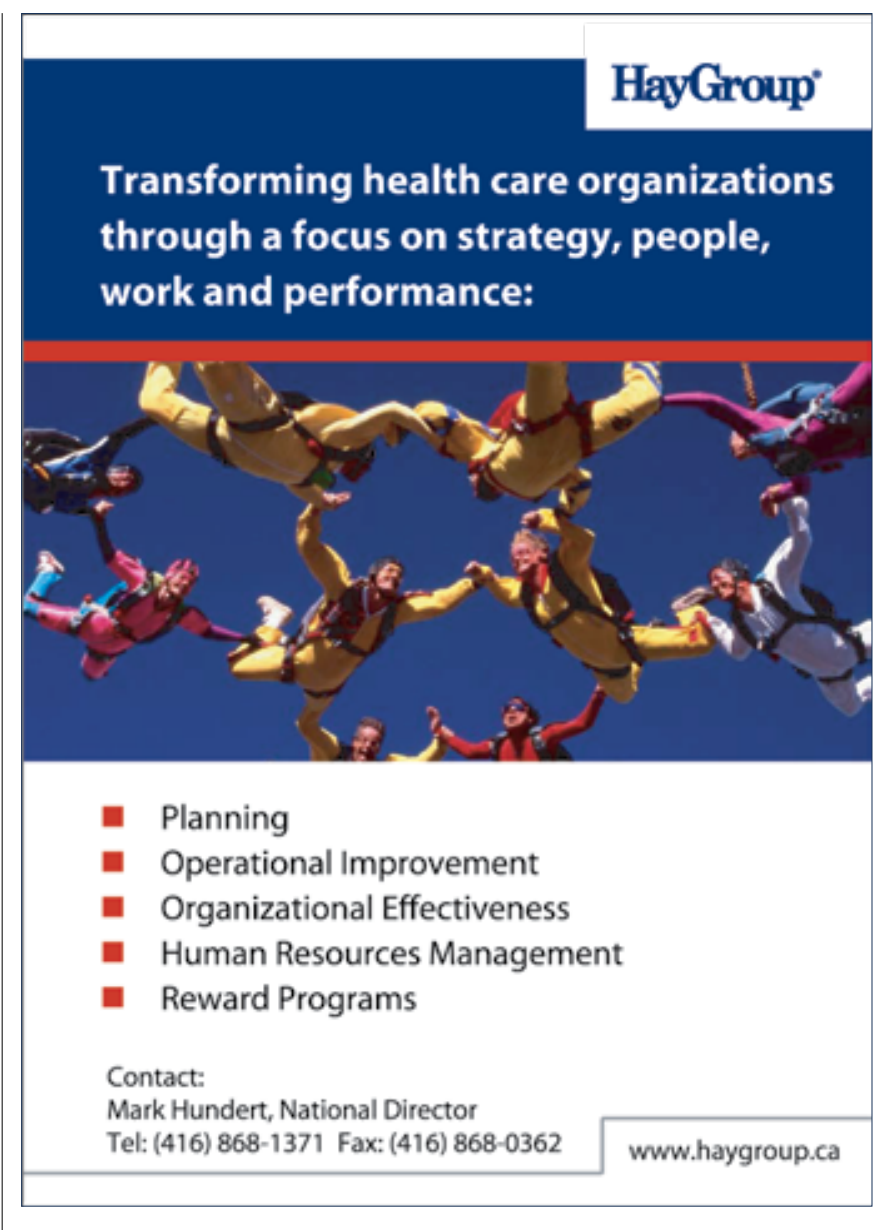

Wilson, K. and M.W. Rosenberg. 2002. "The Geographies of Crisis: Exploring Accessibility to Health Care in Canada." Canadian Geographer 46(3): 223-34.

\section{About the Authors \\ Lyn M. Sibley, PhD, is a member of the Institute for Clinical Evaluative Sciences (ICES) and the Health System Performance Research Network, based out of the Department of Health Policy, Management, and Evaluation, at the University of Toronto, in Toronto, Ontario.}

Richard H. Glazier, MD, MPH, CCFP, FCFP, is a member of ICES and the Centre for Research on Inner City Health at St. Michael's Hospital, Department of Family and Community Medicine, University of Toronto.

\section{* because we're thinking of your health and well being}

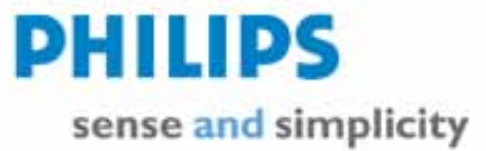

